\title{
THE CHOICE OF ON- OR OFF-PUMP CORONARY BYPASS GRAFTING - A SURGEON'S DILEMMA
}

\author{
Marek Gwozdziewicz ${ }^{\mathrm{a}^{*}}$, Petr Olsak ${ }^{\mathrm{a}}$, Vladimir Lonsky ${ }^{\mathrm{a}}$, Milan Elfmark
}

\author{
a Department of Cardiac Surgery, University Hospital, Olomouc, Czech Republic \\ b Faculty of Physical Culture, Palacký University Olomouc \\ e-mail: gwozdziewicz@email.cz
}

Received: July 22, 2008; Accepted (with revision): November 27, 2008

Key words: Coronary bypass/Off pump

Background: Off-pump coronary bypass grafting (OPCAB) is a routine method of heart revascularization. This study was designed to compare the results of OPCAB and ONCAB performed by a single surgeon at our institution over a 3-year period.

Methods: The study enrolled 345 patients undergoing elective myocardial revascularization procedures, of which 173 (50.1\%) were OPCAB and 172 (49.9\%) were ONCAB. The postoperative outcomes of both groups were analyzed, retrospectively.

Results: The mean number of grafts was significantly lower in the OPCAB group (2.9) than in the ONCAB group (3.7). There were no postoperative myocardial infarctions or hospital deaths in any of the patients. The postoperative total blood loss was significantly higher in the ONCAB group. The frequencies of postoperative confused states, strokes, postoperative transfusions, reoperations for bleeding, and atrial fibrillation, and the durations of intubation, ICU stay, and hospital stay did not differ significantly between the two groups.

Conclusions: The OPCAB procedures are safe and provide good clinical outcomes, similar to those of ONCAB operations. The outcomes of this study favor neither of the compared techniques.

\section{INTRODUCTION}

Off-pump coronary bypass grafting (OPCAB) is a routine method for heart revascularization, but its superiority over conventional on-pump coronary bypass grafting (ONCAB) has not been clarified ${ }^{1}$. One of the most important factors is whether OPCAB is safe and more effective than ONCAB in the hands of a particular surgeon.

This retrospective observational study was undertaken to compare the results of OPCAB and ONCAB performed by a single surgeon at our institution over a 3-year period.

\section{METHODS}

A total of 345 consecutive elective, primary, isolated heart revascularizations were performed between January 2004 and January 2007 by a single surgeon with experience in both ONCAB and OPCAB in our department. The preoperative characteristics of both groups are listed in Table 1.

The ONCAB technique relied on antegrade cold crystalloid cardioplegia. During OPCAB procedure the heart was immobilized with two suction based stabilizers with all peripheral anastomoses being sutured on intracoronary shunts, as described previously ${ }^{2}$. The postoperative outcomes of both groups were analyzed, retrospectively.

This study was approved by the Institutional Review Board of our institution.

\section{Statistical analysis}

The recorded data were statistically analyzed using Statistica 6.0 software (StatSoft, Tulsa, OK). Dependences between variables were evaluated using contingency tables. Continuous variables were compared using the $t$ test, with a $p$ value less than 0.05 considered statistically significant.

\section{RESULTS}

The study enrolled 345 patients undergoing elective myocardial revascularization procedures, of which 173 (50.1\%) were OPCAB and 172 (49.9\%) were ONCAB. The mean ages of the patients undergoing OPCAB and ONCAB were 68.2 and 66.4 years, respectively, and they comprised $30.8 \%$ and $36.4 \%$ females. The postoperative results are listed in Table 2.

Three patients $(1.7 \%)$ in the OPCAB group needed intraoperative conversion to ONCAB owing to hemodynamic instability, and these patients were included in the OPCAB cohort. Table 3 lists separately the characteristics and outcomes of these patients.

Patients who underwent OPCAB presented preoperatively with better ejection fraction ( $53.4 \%$ vs. $50.7 \%$ ) and a lower frequency of insulin-dependent diabetes mellitus ( $11.5 \%$ vs. $18.6 \%$ ), and they were slightly older than ONCAB patients (68.1 vs. 66.5).

The mean number of grafts was significantly lower in the OPCAB group (2.9) than in the ONCAB group (3.7), 
Table 1. The preoperative characteristics of OPCAB and ONCAB patients.

\begin{tabular}{|l|c|c|c|}
\hline & $\begin{array}{c}\text { OPCAB } \\
\mathrm{n}(\%)\end{array}$ & $\begin{array}{c}\text { ONCAB } \\
\mathrm{n}(\%)\end{array}$ & $p$ Value \\
\hline Patients & $173(50.1)$ & $172(49.9)$ & $>0.9$ \\
\hline Age & $68.2 \pm 9.1$ & $66.4 \pm 8.5$ & 0.07 \\
\hline Female & $63(36.4)$ & $53(30.8)$ & 0.27 \\
\hline EF & $53.4(25-65 \%)$ & $50.7(25-65 \%)$ & 0.01 \\
\hline LM & $42(24.2)$ & $50(29)$ & 0.32 \\
\hline Hypertension & $142(82)$ & $136(79)$ & 0.48 \\
\hline Dyslipidemia & $123(71)$ & $120(69.8)$ & 0.8 \\
\hline Diabetes mellitus ID & $20(11.5)$ & $32(18.6)$ & 0.06 \\
\hline Diabetes mellitus NID & $45(26)$ & $46(26.7)$ & 0.93 \\
\hline Obesity & $34(19.6)$ & $33(19.2)$ & 0.97 \\
\hline PCI & $15(8.6)$ & $15(8.7)$ & 0.2 \\
\hline Stroke & $9(5.2)$ & $15(8.7)$ & .29 \\
\hline
\end{tabular}

EF, ejection fraction; LM, left main disease (> 50 \% stenosis); ID, insulin dependent; NID, non- insulin dependent; PCI, percutanous coronary intervention

Table 2. The postoperative results of OPCAB and ONCAB patients.

\begin{tabular}{|l|c|c|c|}
\hline & $\begin{array}{c}\text { OPCAB } \\
\mathrm{n}(\%)\end{array}$ & $\begin{array}{c}\text { ONCAB } \\
\mathrm{n}(\%)\end{array}$ & $p$ Value \\
\hline Patients & $173(50.1)$ & $172(49.9)$ & $>0.9$ \\
\hline Number of grafts & $2.9(1-5)$ & $3.7(1-5)$ & $<0.01$ \\
\hline ITA & $157(90.7)$ & $162(94.1)$ & 0.49 \\
skeletonized & $61(35.3)$ & $67(38.9)$ & $<0.01$ \\
\hline RA & $18(10.4)$ & $8(4.6)$ & $<0.01$ \\
\hline Mean total blood loss & $888 \mathrm{ml}$ & $1010 \mathrm{ml}$ & 0.08 \\
\hline Transfusions & $44(25)$ & $58(33.7)$ & 0.61 \\
\hline Reoperation for bleeding & $2(1.2)$ & $1(0.6)$ & 0.46 \\
\hline Sternotomy infection superficial & $8(4.6)$ & $11(6.4)$ & 0.47 \\
with sternum dehiscence & $1(0.5)$ & $2(1.2)$ & 0.78 \\
\hline Pleural effusion requiring puncture & $8(4.6)$ & $7(4)$ & 0.24 \\
\hline Confused state & $8(4.6)$ & $13(7.6)$ & 0.47 \\
\hline Stroke & $1(0.5)$ & $2(1.2)$ & 0.38 \\
\hline Atrial fibrilation & $45(26)$ & $38(22)$ & \\
\hline Myocardial infarction & 0 & 0 & 0.93 \\
\hline Hospital mortality & 0 & 0 & 0.96 \\
\hline Post-op intubation (hours) & $8.6(3-29)$ & $8.9(2-24)$ & 0.11 \\
\hline ICU length of stay (days) & $1.4(1-13)$ & $1.4(1-9)$ & \\
\hline Hospital length of stay (days) & $9(6-45)$ & $9.4(6-63)$ & \\
\hline
\end{tabular}

with the OPCAB group having 6 patients with five peripheral anastomoses and 39 patients with four grafts. Figure 1 shows the distribution of the grafts in the two groups in terms of the numbers of sutured peripheral anastomoses. The internal thoracic artery (ITA) was used in $90.7 \%$ and $94.1 \%$ of OPCAB and ONCAB patients, respectively, and was harvested as a skeleton in $35.3 \%$ and $37.1 \%$ of them. When the ITA was harvested as a pedicle, the postoperative blood loss was significantly higher in the ONCAB group than in the OPCAB group. The ITA could not be used due to intraoperative injury in three $(0.8 \%)$ of the patients. The radial artery was used as one of the conduits more often in the OPCAB group (10.4\%) than in the ONCAB group ( $4.6 \%$ ).

There were no postoperative myocardial infarctions or hospital deaths in any of the patients. The postoperative total blood loss was significantly higher in the ONCAB group. However, the frequencies of postoperative confused states, strokes, postoperative transfusions, reoperations for bleeding, and atrial fibrillation, and the durations of intubation, ICU stay, and hospital stay did not differ significantly between the two groups. 
Table 3. Characteristics and outcomes of patients converted to ONCAB.

\begin{tabular}{|l|l|l|l|}
\hline & Patient 1 & Patient 2 & Patient 3 \\
\hline age & 52 & 75 & 76 \\
\hline female & yes & yes & yes \\
\hline EF (\%) & 55 & 65 & 65 \\
\hline LM & 0 & yes & yes \\
\hline Number of grafts & 4 & 3 & 3 \\
\hline Mean total blood loss (ml) & 580 & 1180 & 890 \\
\hline Sternal infection & 0 & yes & 0 \\
\hline Confused state & 0 & 0 & yes \\
\hline Post-op intubation (hours) & 5 & 16 & 14 \\
\hline ICU length of stay (days) & 1 & 1 & 1 \\
\hline Hospital length of stay (days) & 7 & 41 & 16 \\
\hline
\end{tabular}

\section{DISCUSSION}

According to the 2005 AHA Scientific Statement, both the OPCAB and standard CABG procedures usually result in excellent outcomes, with neither being considered inferior ${ }^{1}$. Although this recommendation is based on scientific evidence, it appears unlikely that exposing or not exposing a patient to extracorporeal circulation makes no difference.

In daily practice, a surgeon should precede depending upon his or her own results. In this study we compared the outcomes of patients undergoing $\mathrm{OPCAB}$ and $\mathrm{ONCAB}$ procedures. The approximately equal numbers (173 vs. 172) of consecutive, elective patients were operated by a single surgeon who was experienced in both $\mathrm{OPCAB}$ and ONCAB procedures. Significantly fewer grafts were performed in the OPCAB group (2.9 vs. 3.7), which was due to the fact that patients with 1-2 vessel disease were

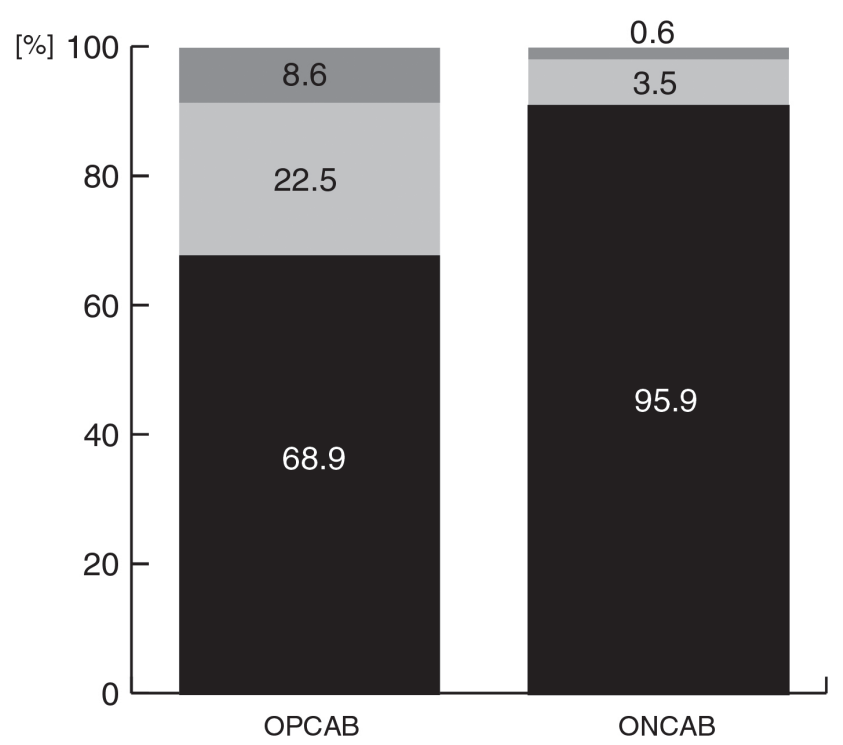

Fig. 1. The distribution of the grafts in the two groups (OPCAB and ONCAB) in terms of the number of sutured peripheral anastomoses. (grey, 1 anastomosis; white 2 anastomoses; black, 3 and more anastomoses) primarily indicated for the OPCAB procedure. The only significant difference between the two groups was the postoperative blood loss, which was higher in the ONCAB group. In contrast to previously published studies, we found no significant difference in the durations of intubation, ICU stay, hospitalization and mortality between the groups $^{3-8}$. Also, the frequencies of postoperative episodes of neurological complications, reoperations for bleeding, atrial fibrillations, and sternum infections did not differ between the groups. From this study we can conclude that $\mathrm{OPCAB}$ procedures are safe and provide good clinical outcomes, similar to those of ONCAB operations, in a selected group of patients. The outcomes of this study favor neither of the compared techniques, and although the OPCAB group comprised more so called easy patients (good LV, less grafts) the dilemma remains. Should we continue to perform OPCAB in these patients, which is always technically more demanding, or should we just put a cross clamp and enjoy the bloodless and motionless operating field?

\section{REFERENCES}

1. Sellke FW, DiMaio JM, Caplan LR, Ferguson TB, Gardner TJ, Hiratzka LF, Isselbacher EM, Lytle BW, Mack MJ, Murkin JM, Robbins RC; American Heart Association. Comparing on-pump and off-pump coronary artery bypass grafting: numerous studies but few conclusions: a scientific statement from the American Heart Association council on cardiovascular surgery and anesthesia in collaboration with the interdisciplinary working group on quality of care and outcomes research. Circulation 2005; 111(21):2858-64.

2. Gwozdziewicz M, Nemec P, Simek M, Hajek R, Troubil M. Sequential bypass grafting on the beating heart: blood flow characteristics. Ann Thorac Surg. 2006; 82(2):620-3.

3. Palmer G, Herbert MA, Prince SL, Williams JL, Magee MJ, Brown P, Katz M, Mack MJ. Coronary Artery Revascularization (CARE) registry: an observational study of on-pump and off-pump coronary artery revascularization. Ann Thorac Surg. 2007:986-91; discussion 991-2.

4. Al-Ruzzeh S, George S, Bustami M, Wray J, Ilsley C, Athanasiou T, Amrani M. Effect of off-pump coronary artery bypass surgery on clinical, angiographic, neurocognitive, and quality of life outcomes: randomised controlled trial. BMJ. 2006; 332(7554):1365.

5. Kobayashi J, Tashiro T, Ochi M, Yaku H, Watanabe G, Satoh T, Tagusari O, Nakajima H, Kitamura S; Japanese Off-Pump Coronary Revascularization Investigation (JOCRI) Study Group. Early out- 
come of a randomized comparison of off-pump and on-pump multiple arterial coronary revascularization. Circulation 2005; 112(9 Suppl):I338-43.

6. Racz MJ, Hannan EL, Isom OW, Subramanian VA, Jones RH, Gold JP, Ryan TJ, Hartman A, Culliford AT, Bennett E, Lancey RA, Rose EA. A comparison of short- and long-term outcomes after off-pump and on-pump coronary artery bypass graft surgery with sternotomy. J Am Coll Cardiol. 2004; 43(4):557-64.

7. Puskas JD, Williams WH, Duke PG, Staples JR, Glas KE, Marshall JJ, Leimbach M, Huber P, Garas S, Sammons BH, McCall SA, Petersen RJ, Bailey DE, Chu H, Mahoney EM, Weintraub WS, Guyton RA. Off-pump coronary artery bypass grafting provides complete revascularization with reduced myocardial injury, transfusion requirements, and length of stay: a prospective randomized comparison of two hundred unselected patients undergoing offpump versus conventional coronary artery bypass grafting. J Thorac Cardiovasc Surg. 2003; 125(4):797-808.

8. Puskas JD, Kilgo PD, Lattouf OM, Thourani VH, Cooper WA, Vassiliades TA, Chen EP, Vega JD, Guyton RA. Off-pump coronary bypass privides reduced mortality and morbidity and equivalent 10-year survival. (http://www.ncbi.nlm.nih.gov/pubmed/1880514 9?ordinalpos=5\&ittool-EntrezSystem2.PEntrez.Pubmed.Pubmed ResultsPanel.Pubmed DefaultReportPanel.Pubmed RVDocSum) Ann Thorac Surg. 2008; 86(4):1139-46. 